\title{
Protective Lung Ventilation Strategy Combined with Prone Position in the Treatment of Severe Pulmonary Aspiration Syndrome: An Experimental Study
}

Nebojsa Videnovic ${ }^{1,2^{*}}$, Jovan Mladenovic ${ }^{1,3}$, Aleksandar Pavlovic ${ }^{1,2}$, Slađana Trpkovic ${ }^{1,2}$, Simon Nikolic ${ }^{1}$, Milan Filipovic ${ }^{1,3}$, Valentina Videnovic ${ }^{4}$ and Rasa Mladenovic ${ }^{1}$

${ }^{1}$ Medical Faculty, University of Pristina, Kosovska Mitrovica, Serbia

${ }^{2}$ Department of Anesthesiology, Clinical Center Gracanica, Serbia

${ }^{3}$ Department of Surgery, Clinical Center Gracanica, Serbia

${ }^{4}$ Department of Neonatology, General Hospital in Leskovac, Serbia

*Corresponding author: Nebojsa Videnovic, Department of Anesthesiology, Clinical Center Gracanica, Serbia, Tel: 381652229590; E-mail: vidneb@yahoo.com Received date: May 17, 2018; Accepted date: June 25, 2018; Published date: June 27, 2018

Copyright: $\odot 2018$ Videnovic N, et al. This is an open-access article distributed under the terms of the Creative Commons Attribution License, which permits unrestricted use, distribution, and reproduction in any medium, provided the original author and source are credited.

\begin{abstract}
Introduction: The aim of this study was to evaluate how the applied positive ends expiratory pressure and prone position affected patho-histological changes in lungs, as well as parameters of ventilation, oxygenation and acidbase status in the first hours after aspiration in experimental animals.

Methods: This prospective study included 15 experimental animals. The acid aspiration pneumonitis was induced by infusing gastric juice $(2 \mathrm{ml} / \mathrm{kg}$ body weight) into the tube lumen during two-minute ventilation. In the first group, conventional ventilation with a tidal volume of $15 \mathrm{ml} / \mathrm{kg}$ body weight was applied. The piglets of the other group were ventilated at lower tidal volume $(6 \mathrm{ml} / \mathrm{kg}$ body weight) whereas the third group received protective lung ventilation (Vt-6 ml/kg and positive end-expiratory pressure of 5 to $10 \mathrm{~cm} \mathrm{H}_{2} \mathrm{O}$ )
\end{abstract}

Results: Ventilation with a volume of $15 \mathrm{ml} / \mathrm{kg}$ body weight resulted in the formation of announced alveolar and interstitial edema, distension and rupture of alveoli, air leaks in lung tissue, pronounced cellular infiltration and pulmonary hemorrhage. Ventilation at a low tidal volume is characterized by micro atelectasis, alveolar collapse and pronounced cellular infiltration in interstitial and alveolar spaces. The absence of alveolar and interstitial edema, micro atelectasis, significant cellular infiltration predominantly in the pulmonary region, moderately distended alveoli and dilated small airways characterize protective ventilation of the lungs.

Conclusion: Lung protective ventilation in the first hours after aspiration can prevent and/or reduce the progression of lung injury.

Keywords: Lung; Aspiration; Mechanical ventilation

\section{Introduction}

Globally, Aspiration syndromes include all conditions in which foreign substances are inhaled into the lungs. Most commonly, aspiration syndromes involve oral or gastric contents associated with gastro-esophageal reflux, swallowing dysfunction, neurological disorders, structural abnormalities, surgical procedures and anesthesia. Pulmonary aspiration syndromes are a common cause of morbidity and mortality. The type of syndrome depends on the quantity and nature of the aspirated material as well as its chronicity. The most common syndromes include aspiration pneumonia, diffuse aspiration bronchiolitis and aspiration pneumonitis [1,2]. The syndrome defined as acute lung injury after the inhalation of gastric content is Mendelson's syndrome, reported in obstetrical cases in 1946. Classically, there is a history of vomiting after inhalation anesthesia, either during the operation or in the early postoperative period. However, due to the wide use of general anesthesia, this iatrogenic complication may occur in other types of surgical patients. Pulmonary aspiration of gastric or esophageal contents is uncommon; however, it is one of the most severe complications in the perioperative period. Perioperative pulmonary aspiration is an infrequent but is still a leading cause of anesthesia-related morbidity and mortality. The most consistent risk factors related to anesthesia are light anesthesia, residual neuromuscular blockade after anesthesia, intermittent positive pressure ventilation particularly with high airway pressure, and prolonged anesthesia. The presence of a supra-glottic airway inserted in hypo-pharynx, multi attempts at tracheal intubation, incorrectly inserted airway, the classic laryngeal mask, airway removal and cuff deflation during recovery of anesthesia, and exchange to a tracheal tube from supra-glottic airway increase the risk of aspiration and regurgitation. Even if patients have no predisposing factors, they may become at risk of pulmonary aspiration from a surgical procedure. Patients who are undergoing emergency procedures, bariatric surgery, upper abdominal surgery and laparoscopic surgery should be considered at risk [3]. The aspiration is associated with possible clinical outcomes, ranging from mild asymptomatic limited episodes of bronchial injury up to the development of a severe acute respiratory distress syndrome [4]. The clinical syndrome resulting from such aspiration will depend both on the quantity and nature of the aspirate as well as the individual host response. Aspiration of gastric fluids may 
Citation: Videnovic N, Mladenovic J, Pavlovic A, Trpkovic S, Nikolic S, et al. (2018) Protective Lung Ventilation Strategy Combined with Prone Position in the Treatment of Severe Pulmonary Aspiration Syndrome: An Experimental Study. J Vet Sci Technol 9: 549. doi: $10.4172 / 2157-7579.1000549$

Page 2 of 9

cause damage to airway epithelium, not only because acidity is toxic to bronchial epithelial cells but also due to the effect of digestive enzymes such as pepsin and bile salts [5]. Aspiration of large amounts of gastric contents can cause acute respiratory distress over minutes to one or two hours after aspiration. Acidity of gastric contents results in chemical burn of the trachea-bronal tree. If the $\mathrm{pH}$ of the aspirated fluid is less than 2.5 and the volume of aspirate is greater than. 0.3 $\mathrm{ml} / \mathrm{kg}$ of body weight (b.w.), $20-25 \mathrm{ml}$ in adults, it has a greater potential for causing chemical pneumonia. Inhalation of acidic gastric contents in the lower respiratory tract causes the development of chemical pneumonitis with subsequent airway inflammation [6].

Alveolar epithelium and the capillary endothelium are damaged. Vascular permeability to proteins increases, leading to their accumulation in lung interstitium and the alveolar spaces. Bronchospasm and reduced surface of the respiratory membrane may increase ventilation/perfusion mismatch, leading to progressive hypoxemia, hypercapnia, and acidosis.

The treatment depends on the time that has passed from aspiration to the diagnosis, the degree of acidity, the volume of the aspirate, the presence of food and bacteria and the patient's respiratory status prior to aspiration. The treatment implies: the establishing and maintaining the airway, pharyngeal, laryngeal, tracheal suction and the recovery of circulating volume, the use of corticosteroids, bronchodilators, antibiotics, $\mathrm{H}_{2}$ blockers and proton pump inhibitors, handling acidosis [7].

In clinical cases of severe aspiration pneumonitis, it is often necessary to intubate the patient and apply some form of mechanical ventilation to the lungs. While mechanical ventilation clearly saves lives, inappropriate ventilation can result in complications, some of which may directly endanger the life of patients [8,9]. Although mechanical ventilation is life-saving in that it replaces spontaneous breathing, it has been established that it affects all of the body systems, respiratory in particular. The weight of the evidence obtained from studies in experimental animals, correlative human studies, and intervention human studies address the rather convincing side effects of various ventilator strategies in clinical practice [10-13].

The aim of this study was to evaluate how the applied positive end expiratory pressure (PEEP) and prone position affected pathohistological changes in lungs as well as parameters of ventilation, oxygenation and acid-base status in the first hours after aspiration in experimental animals.

\section{Materials and Methods}

This prospective and randomised study used 15 Danish Landrace piglets, 3-4 months old. Piglets were kept in isolation room $24 \mathrm{~h}$ prior to experiment commencement and were not fed 6 hours prior to initiation of the research protocol. Piglets were randomly assigned to three study groups, each consisting of 5 animals, using the sealed envelope method. A secure airway was established by performing tracheostomy and placing an armed (size 5.5) the In this way, the difficult or impossible oro-tracheal intubation was avoided. The intervention was performed using anesthetic combination of ketamine hydrochloride $(20 \mathrm{mg} / \mathrm{kg}$ body weight $)$ and midazolam $(0.5 \mathrm{mg} / \mathrm{kg}$ body weight). Anesthetics were administered as an intramuscular injection into the neck muscles. The onset of anesthesia occurred within 3 to 5 minutes after the administration of anesthetics. This type of anesthesia allowed the preservation of spontaneous breathing during the tracheostomy. Peripheral venous access was obtained by an earlobe vein cannulation. Intra-arterial catheter was placed into femoral artery and samples for blood gas analysis were collected. Following the establishment of the airway, anesthesia was maintained for 7 hours with TIVA of propofol (0.3-0.7 $\mathrm{mg} / \mathrm{kg} / \mathrm{min}$. body weight) and fentanyl $(2-9 \mu \mathrm{g} / \mathrm{kg} / \mathrm{min}$. body weight) (Braun FM perfusor), muscle relaxation was achieved by fractional administration of pancuronium bromide at the intravenous dose of $0.2 \mathrm{mg} / \mathrm{kg}$ body weight (as shown in Table 1).

\begin{tabular}{|l|l|}
\hline Anesthetic/Analgesic/ Muscle relaxant & Dose \\
\hline Ketamine hydrochloride & $\begin{array}{l}\text { Loading dose } 20 \mathrm{mg} / \mathrm{kg} \text { body } \\
\text { weight, intramuscular }\end{array}$ \\
\hline Midazolam & $\begin{array}{l}\text { Loading dose } 0,5 \mathrm{mg} / \mathrm{kg} \text { body } \\
\text { weight, intramuscular }\end{array}$ \\
\hline Propofol & $\begin{array}{l}0.03-0.7 \quad \mathrm{mg} / \mathrm{kg} / \mathrm{min} \quad \text { body } \\
\text { weight, TIVA }\end{array}$ \\
\hline Fentanyl & $\begin{array}{l}\text { Loading dose: } 2-9 \quad \mu g / \mathrm{kg} / \mathrm{h}, \\
\text { body weight. TIVA }\end{array}$ \\
\hline Pancuronium bromide & $\begin{array}{l}0,2 \quad \mathrm{mg} / \mathrm{kg} \mathrm{body} \mathrm{weight,} \\
\text { intravenous }\end{array}$ \\
\hline
\end{tabular}

Table 1: Protocol of anesthesia.

After the establishment of the airway and induction to anesthesia, the gastric juice in the volume of $2 \mathrm{ml} / \mathrm{kg}$ body weight was infused into the lungs of the piglets through the endotracheal tube. Piglets were then ventilated using Ambu bag for 2 minutes. In this way, aspiration syndrome was iatrogenically induced. Ventilators were then connected through an endotracheal tube (Dräger Savina $\left.{ }^{\circledR} 300\right)$. In all three groups, intermittent positive pressure ventilation (IPPV) was used for seven hours.

In VHV group (ventilation at high tidal volume) piglets were ventilated with a tidal volume of $15 \mathrm{ml} / \mathrm{kg}$ body weight, respiratory rate of 15/min., inspiratory/expiratory ratio (I:E) 1:2 (1.7 s/3.3 s) and PEEP of zero. In VLV group (ventilation at low tidal volume) parameters were set as: tidal volume of $6 \mathrm{ml} / \mathrm{kg}$ body weight, respiratory rate of 15/ min, I:E ratio (1:2), PEEP zero. In the third studied group lung protective ventilation (LPV group) was administered with a breathing volume of $6 \mathrm{ml} / \mathrm{kg}$ body weight, breathing rate of 15/min, I:E ratio 1:2 and PEEP levels of $5 \mathrm{~cm} \mathrm{H} \mathrm{H}_{2} \mathrm{O}$ in the first 4 hours followed by PEEP levels of $10 \mathrm{~cm} \mathrm{H}_{2} \mathrm{O}$ for another 3 hours. The concentration of inspired oxygen $\left(\mathrm{FiO}_{2}\right)$ was $40 \%$ for all experimental animals (Table 2).

\begin{tabular}{|l|l|l|l|}
\hline Ventilator Parameter & VHV- group & VLV- group & LPV- group \\
\hline $\begin{array}{l}\text { Model of mechanical } \\
\text { ventilation }\end{array}$ & IPPV & IPPV & IPPV \\
\hline $\begin{array}{l}\text { Duration of mechanical } \\
\text { ventilation }\end{array}$ & $7 \mathrm{~h}$ & $7 \mathrm{~h}$ & $7 \mathrm{~h}$ \\
\hline $\begin{array}{l}\text { Fraction of inspired oxygen } \\
\left(\mathrm{FiO}_{2}\right)\end{array}$ & $40 \%(0,4)$ & $40 \%(0,4)$ & $40 \%(0,4)$ \\
\hline Tidal volume (Vt) & $15 \mathrm{ml} / \mathrm{kg}$ & $6 \mathrm{ml} / \mathrm{kg}$ & $6 \mathrm{ml} / \mathrm{kg}$ \\
\hline PEEP & $0 \mathrm{H}_{2} \mathrm{O}$ & $0 \mathrm{H}_{2} \mathrm{O}$ & $\begin{array}{l}5(3 \mathrm{~h})-10(4 \mathrm{~h}) \\
\mathrm{H}_{2} \mathrm{O}\end{array}$ \\
\hline Respiratory rate & $\begin{array}{l}12 \text { breaths per } \\
\text { minute }\end{array}$ & $\begin{array}{l}12 \text { breaths per } \\
\text { minute }\end{array}$ & $\begin{array}{l}12 \text { breaths per } \\
\text { minute }\end{array}$ \\
\hline
\end{tabular}


Citation: Videnovic N, Mladenovic J, Pavlovic A, Trpkovic S, Nikolic S, et al. (2018) Protective Lung Ventilation Strategy Combined with Prone Position in the Treatment of Severe Pulmonary Aspiration Syndrome: An Experimental Study. J Vet Sci Technol 9: 549. doi: $10.4172 / 2157-7579.1000549$

Page 3 of 9

\begin{tabular}{|l|l|l|l|}
\hline I:E ratio & $01: 02$ & $01: 02$ & $01: 02$ \\
\hline Inspiratory time & $1.7 \mathrm{~s}$ & $1.7 \mathrm{~s}$ & $1.7 \mathrm{~s}$ \\
\hline Expiratory time & $3.3 \mathrm{~s}$ & $3.3 \mathrm{~s}$ & $3.3 \mathrm{~s}$ \\
\hline
\end{tabular}

\section{Statistical analysis}

The analysis of obtained data was performed using the SPSS 22.0 software (Version 22.0, SPSS, Inc, Chicago, IL) as well as Microsoft Excel 2010. Descriptive statistics were used to determine the relative numbers and measures of the central tendency: the arithmetic mean

Table 2: Initial ventilator settings for pigs. VHV-Ventilation High Volume; VLV-Ventilation Low Volume; LPV-Lung Protective Ventilation; PEEP-Positive End-Expiratory Pressure; IPPVIntermittent Positive-Pressure Ventilation; I:E ratio-the ratio of the duration of inspiration to the duration of expiration; s-second; hhours.

Experimental animals from VHV and VLV groups were placed in supine position during mechanical ventilation. In the LPV group, a prone position was used after aspiration and the two-minute ventilation with Ambu bag. Assessment of the pulmonary function of experimental animals was performed by monitoring parameters of ventilation, oxygenation and acid-base status. Monitoring of ventilation included the following parameters: tidal volume $\left(\mathrm{V}_{\mathrm{t}}\right)$, minute volume ventilation, peak pressure $\left(\mathrm{P}_{\text {peak }}\right)$, plato pressure $\left(\mathrm{P}_{\text {plato }}\right)$, partial pressure of carbon dioxide in the arterial blood of experimental animals $\left(\mathrm{PaCO}_{2}\right)$. Monitoring of oxygenation involved saturation of hemoglobin in arterial blood $\left(\mathrm{SaO}_{2}\right)$ and partial pressure of oxygen in arterial blood $\left(\mathrm{PaO}_{2}\right)$. Evaluation of acid-base status was performed on the basis of the values of arterial blood $\mathrm{pH}$. Values of the intrapulmonary shunt (Qs/Qt) were also monitored during the implementation of the mechanical ventilation of lungs of experimental animals. For the monitoring of experimental animals during the implementation of mechanical ventilation of lungs we used: Monitor Infinity Gamma XL-Dräger, gas analyzer GEM Premier 3000 Instrumentation Laboratory and monitor incorporated in the ventilator type Dräger Savina ${ }^{\oplus} 300$. Parameters were analysed at following intervals of research protocol:

$\mathrm{T}_{0}$-after the establishment of the airway and placement of intraarterial catheter (spontaneous ventilation);

$\mathrm{T}_{1}-5$ min. after iatrogenic aspiration and the commencement of mechanical ventilation of the lungs with preset parameters;

$\mathrm{T}_{2}$-after 4 hours of ventilation

$\mathrm{T}_{3}$-after 7 hours of ventilation.

After the animals were ventilated, (10 from each lobe) were collected and stored in containers with formalin and sent for histologic examination. The examination was performed by a pathologist who was not familiar with the research protocol and model of applied mechanical ventilation of the lungs. The tissue was fixed $24 \mathrm{~h}$ in $4 \%$ neutral buffered formalin, processed with a standard sequence of water-alcohol-xylene-paraffin, paraffin cast in molds, cut on a rotary microtome LEICA RM 2235 and routinely stained with hem alum and eosin. Graduation degree of the histo-pathological changes in the lungs of piglets was based on the following divisions: (4) expressed; (3) moderately expressed; (2) minimally present (expressed) and (1) histopathological changes not present. Histological samples were observed using Axiovert $200 \mathrm{M}$ Inverted Microscopes-Carl Zeiss at an increment of x100. After completion of the, all animals received an injection of $7.4 \%$ potassium chloride solution and were sacrificed. proportions (percentages). Monitored parameters were recorded and compared using Student's t-test, Anova test and Tukey HSD ("Honestly Significant Difference") post-hoc test (). For the comparison of pathohistological changes, the non-parametric Kruskal-Wallis test and Mann-Whitney U-test were used. $\mathrm{P}$ values $>0.05$ were considered statistically non-significant, $\mathrm{p}$-values $<0.05$ were considered statistically significant and $\mathrm{p}$-values $<0.01$ were considered statistically highly significant for all comparisons.

\section{Results}

\section{Body weight of experimental animals and statistical analysis}

Table 3 provides the values of average body weight and its standard deviation. The comparative analysis of these values did not give a statistical significance $(\mathrm{p}<0.01)$ between the study groups of experimental animals.

\begin{tabular}{|l|l|l|l|}
\hline Group & VHV group & VLV group & LPV group \\
\hline $\begin{array}{l}\text { Body } \\
\text { weight } \\
\pm \text { SD) }\end{array}$ & $27.3 \pm 2.4$ & $25.7 \pm 3.3$ & $26.6 \pm 2.5$ \\
\hline $\begin{array}{l}\text { Anova test } \\
(p \text { value })\end{array}$ & 0.6655 & LVV vs LPV $=0.819788$ \\
\hline $\begin{array}{l}\mathrm{t}-\text { test }(p \\
\text { value })\end{array}$ & CV vs LVV=0.6399 & CV vs LPV $=0.6635$ & \\
\hline
\end{tabular}

Table 3: Body weight of experimental animals and statistical analysis (t-test and Anova test). \#Data are presented as mean \pm SD (standard deviation); VHV-Ventilation High Volume; VLV-Ventilation Low Volume; LPV-Lung Protective Ventilation; $\mathrm{p}>0.05$-non-significant; $\mathrm{p}<0.05$-significant; $\mathrm{p}<0.01$-highly significant.

\section{Pathohistological changes}

Pathohistological specimen in all tested groups exhibited polymorphism. Different forms of applied mechanical ventilation benefit and intensify the occurrence of certain microscopic changes in the lung tissue of the piglets.

VHV group-Pathohistological changes: Pronounced alveolar and interstitial edema. Minimal distension of the alveoli is present with interruptions in the continuity of the alveolar walls. Certain specimens revealed air leaks in the lung tissue, occurrence of bleeding into the lung parenchyma. The collapse of the alveoli and micro atelectasis present in all regions of the lung, more pronounced in the dorsal parts of the lungs. Significant cellular infiltration (Figure 1). 
Citation: Videnovic N, Mladenovic J, Pavlovic A, Trpkovic S, Nikolic S, et al. (2018) Protective Lung Ventilation Strategy Combined with Prone Position in the Treatment of Severe Pulmonary Aspiration Syndrome: An Experimental Study. J Vet Sci Technol 9: 549. doi: $10.4172 / 2157-7579.1000549$

Page 4 of 9

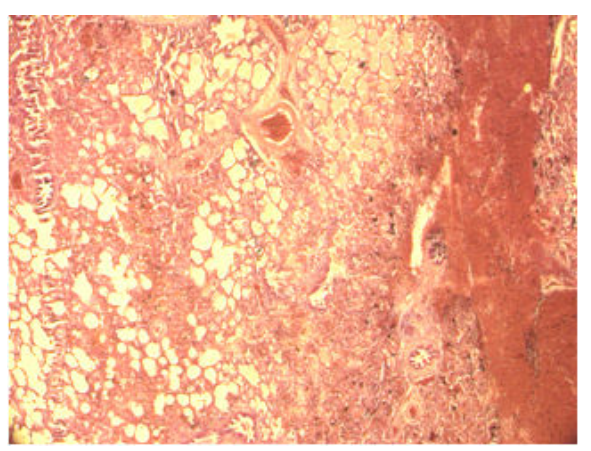

Figure 1: Pronounced alveolar and interstitial edema. Minimal distension of the alveoli present with interruptions in the continuity of the alveolar walls. Certain specimens revealed air leaks in the lung tissue and occurrence of bleeding into the lung parenchyma. The collapse of the alveoli and micro atelectasis present in all regions of the lung are more pronounced in the dorsal parts of the lungs. Significant cellular infiltration.

VLV group-Pathohistological changes: Prevalent alveolar collapse and micro atelectasis with pronounced interstitial and alveolar edema. Pronounced cellular infiltration of perivascular, interstitial and alveolar space is present and this causes Collapse and obstruction of small airways. On certain specimens, minimally distended alveoli with dilated small airways were observed. Interruptions of the continuity of the alveolar septa were present in a small percentage. No air leaks in lung tissue were observed (Figure 2).

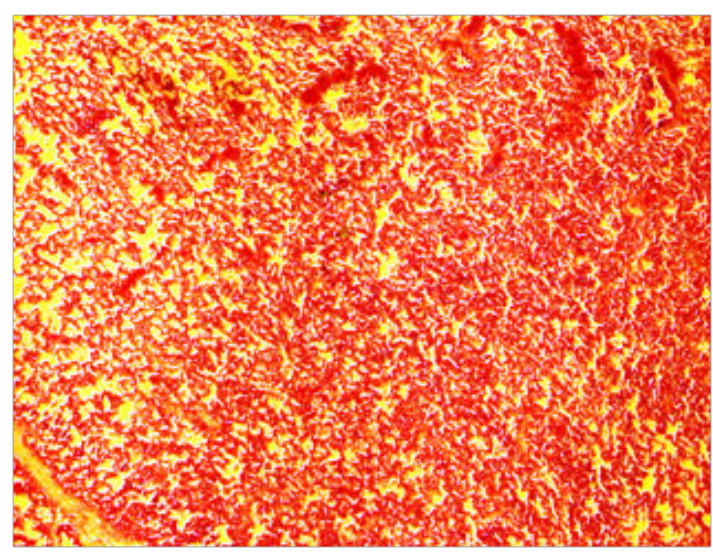

Figure 2: Prevalent alveolar collapse and micro atelectasis with pronounced interstitial and alveolar edema. Pronounced cellular infiltration of perivascular, interstitial alveolar space. Collapse and obstruction of small airways. On certain specimens, minimally distended alveoli with dilated small airways were observed. Interruptions in the continuity and alveolar septa were present in small percentage. No air leaks in lung tissue were observed.

LPV group-Pathohistological changes: Minimally expressed interstitial edema, no alveolar edema. Varying degrees of alveolar distension with moderately prolonged rupture of alveolar walls. In some parts of the lungs air leaks were observed. Small airways dilated. Sub-pleural bleeding mildly expressed. Alveolar collapse and micro atelectasis were not observed. Mild cellular infiltration of the perivascular, interstitial and alveolar spaces (Figure 3).

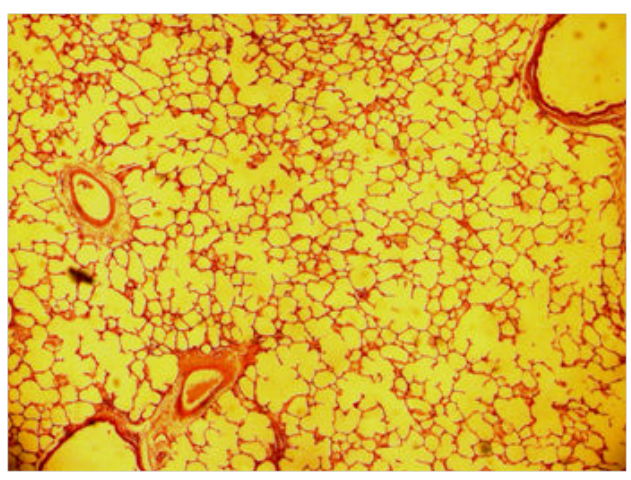

Figure 3: Minimally expressed interstitial edema, no alveolar edema, varying degrees of alveolar distension with moderately pronounced rupture of alveolar walls. In some parts of the lungs air leaks were observed. Small airways dilated. Sub pleural bleeding mildly expressed. Alveolar collapse and micro atelectasis were not observed. Mild cellular infiltration of the perivascular, interstitial and alveolar spaces also.

Nonparametric methods, Kruskal-Wallis test and Mann-Whitney U test revealed a statistically significant difference $(\mathrm{p}<0.01) ;(\mathrm{p}<0.05)$ in occurrence and manifestation of patho-histological changes among the tested groups (Table 4).

\begin{tabular}{|l|l|l|l|l|}
\hline $\begin{array}{l}\text { Histo- } \\
\text { pathological } \\
\text { changes }\end{array}$ & $\begin{array}{l}\text { VHV vs VLV } \\
\text { vs LPV } \\
\text { (Kruskal- } \\
\text { Wallis test, } \\
\text { p-value) }\end{array}$ & $\begin{array}{l}\text { VHV vs VLV } \\
\text { (Mann- } \\
\text { Whytneu } \\
\text { test, } \\
\text { value) }\end{array}$ & $\begin{array}{l}\text { VHV vs LPV } \\
\text { (Mann- } \\
\text { Whytneu } \\
\text { test, } \\
\text { value) }\end{array}$ & $\begin{array}{l}\text { VLV vs LPV } \\
\text { (Mann- } \\
\text { Whytneu } \\
\text { test, p- } \\
\text { value) }\end{array}$ \\
\hline Alveolar edema & 0.00921 & 0.92034 & 0.01208 & 0.01208 \\
\hline Interstitial edema & 0.00921 & 0.92034 & 0.01208 & 0.01208 \\
\hline $\begin{array}{l}\text { Bleeding in the } \\
\text { lung parenchyma }\end{array}$ & 0.00865 & 0.01208 & 0.01208 & 0.67448 \\
\hline $\begin{array}{l}\text { Distension of the } \\
\text { alveoli }\end{array}$ & 0.01287 & 0.0601 & 0.17384 & 0.01208 \\
\hline Rupture of alveoli & 0.01024 & 0.0164 & 0.11642 & 0.03662 \\
\hline Micro atelectasis & 0.00865 & 0.67448 & 0.01208 & 0.01208 \\
\hline $\begin{array}{l}\text { Cellular } \\
\text { infiltration }\end{array}$ & 0.00921 & 0.92034 & 0.75656 & 0.01208 \\
\hline $\begin{array}{l}\text { Small airway- } \\
\text { obstruction }\end{array}$ & 0.01036 & 0.4009 & 0.02144 & 0.01208 \\
\hline $\begin{array}{l}\text { Small airway- } \\
\text { dilatation }\end{array}$ & 0.15684 & 0.11642 & 0.75656 & 0.1443 \\
\hline $\begin{array}{l}\text { The rifts in the } \\
\text { lung parenchyma }\end{array}$ & 0.22953 & 0.29384 & 0.75656 & 0.11642 \\
\hline
\end{tabular}

Table 4: Histo-pathological changes in the lung parenchyma experimental animals (pigs) study groups. \# VHV-Ventilation High Tidal Volume; VLV-Ventilation Low Tidal Volume; LPV-Lung Protective Ventilation. 
Citation: Videnovic N, Mladenovic J, Pavlovic A, Trpkovic S, Nikolic S, et al. (2018) Protective Lung Ventilation Strategy Combined with Prone Position in the Treatment of Severe Pulmonary Aspiration Syndrome: An Experimental Study. J Vet Sci Technol 9: 549. doi: $10.4172 / 2157-7579.1000549$

Page 5 of 9

Comparison of the presence and severity of histo-pathological changes in the lung parenchyma, experimental animals (pigs), study groups (1-no expressed, 2-minimum expressed, 3-moderately expressed, 4-expressed). By testing differences of histo-pathological changes in the lungs of experimental animals in the study groups, using Kruskal-Wallis and Mann-Whytneu U test, we come to the conclusion that there is a statistically significant difference $(\mathrm{p}<0.05)$ and highly significant difference $(\mathrm{p}<0.01)$.

\section{Ventilation, oxygenation and acid-base status}

The greatest increase in $\mathrm{P}_{\text {peak }}$ and $\mathrm{P}_{\text {plato }}$ was recorded immediately after the aspiration of gastric content into the lungs of experimental animals (Table 5). This increase is conditioned not only by the presence of gastric contents in the small airways, but also by the resulting bronchospasm and changes in the lungs, which lead to increased respiratory resistance and decreased lung compliance.

\begin{tabular}{|c|c|c|c|c|c|c|c|c|}
\hline Parameters & \multicolumn{4}{|c|}{$\mathrm{P}_{\text {peak }}\left(\mathrm{cm} \mathrm{H}_{2} \mathrm{O}+\right.$ standard deviation $)$} & \multicolumn{4}{|c|}{$\mathbf{P}_{\text {plato }}\left(\mathrm{cm} \mathrm{H}_{2} \mathrm{O}+\right.$ standard deviation) } \\
\hline & \multicolumn{8}{|c|}{ T-intervals } \\
\hline Groups & $\mathrm{T}_{0}$ & $\mathrm{~T}_{1}$ & $\mathrm{~T}_{2}$ & $\mathrm{~T}_{3}$ & $\mathrm{~T}_{0}$ & $\mathrm{~T}_{1}$ & $\mathrm{~T}_{2}$ & $\mathrm{~T}_{3}$ \\
\hline VHV & - & $35 \pm 3.5$ & $33.6 \pm 2.3$ & $31.8 \pm 3.7$ & - & $33.2 \pm 4.1$ & $31.1 \pm 3.9$ & $29.4 \pm 4.7$ \\
\hline VLV & - & $21.4 \pm 3.2$ & $23.4 \pm 3.8$ & $24.9 \pm 3.5$ & - & $20.8 \pm 2.1$ & $22.3 \pm 3.4$ & $23.7 \pm 1.9$ \\
\hline LPV & - & $27.3 \pm 2.5$ & $25.4 \pm 3.3$ & $23.4 \pm 2.3$ & - & $23.4 \pm 1.7$ & $21.5 \pm 2.2$ & $20.2 \pm 3.7$ \\
\hline Anova (p) & - & $<0.01$ & $<0.01$ & $<0.01$ & - & $<0.01$ & $<0.01$ & $<0.01$ \\
\hline \multicolumn{9}{|c|}{ Tukey HSD ("Honestly Significant Difference") Post-hoc Test (p-value) } \\
\hline VVV v VLV & - & $<0.01$ & $<0.01$ & 0.014 & - & $<0.01$ & $<0.01$ & 0.068 \\
\hline$V V V v_{s} L P V$ & - & $<0.01$ & $<0.01$ & $<0.01$ & - & $<0.01$ & $<0.01$ & $<0.01$ \\
\hline VLV $v_{s} L P V$ & - & 0.027 & $<0.596$ & 0.748 & - & $<0.347$ & $<0.92$ & 0.313 \\
\hline
\end{tabular}

Table 5: Review of mean values of peak pressure $\left(\mathrm{P}_{\text {peak }}\right)$, plato pressure $\left(\mathrm{P}_{\text {plato }}\right)$ by time stages $(\mathrm{T})$ of research and testing the significance of differences between study groups using Anova and Tukey HSD Post-hoc Test. VHV-Ventilation High Volume; VLV-Ventilation Low Volume; LPV-Lung Protective Ventilation; $p>0.05$ non-significant; $p<0.05$ significant; $p<0.01$ highly significant.

Ventilation at the tidal volume of $15 \mathrm{ml} / \mathrm{kg}$ body weight (Table 6) led to a gradual decrease in $\mathrm{PaCo}_{2}$ from $45.2 \mathrm{mmHg}\left(\mathrm{T}_{1}\right)$ to $33.8 \mathrm{mmHg}$ $\left(\mathrm{T}_{4}\right)$ after seven hours of mechanical ventilation of the lungs. At the same time this was followed by a gradual increase in $\mathrm{pH}$ from $7.35\left(\mathrm{~T}_{1}\right)$ to $7.44\left(\mathrm{~T}_{4}\right)$.

Ventilation at a low tidal volume $(6 \mathrm{ml} / \mathrm{kg}$ body weight) during seven-hours ventilation caused a significant rise in $\mathrm{PaCo}_{2}$ from 57.6 $\mathrm{mmHg}\left(\mathrm{T}_{1}\right)$ to $98.4 \mathrm{mmHg}\left(\mathrm{T}_{4}\right)$ with a simultaneous drop in $\mathrm{pH}$ of arterial blood to a value of $7.0\left(\mathrm{~T}_{4}\right)$. This type of ventilation protocol results in severe hypercapnia with severe respiratory acidosis (Table 6).

Protective ventilation (Vt $6 \mathrm{ml} / \mathrm{kg}$ body weight, PEEP $5 \mathrm{~cm} \mathrm{H}_{2} \mathrm{O}(3$ hours) $-10 \mathrm{~cm} \mathrm{H} \mathrm{H}_{2} \mathrm{O}$ (4 hours) resulted in gradual increase in $\mathrm{PaCo}_{2}$ from $45.4 \mathrm{mmHg}\left(\mathrm{T}_{1}\right)$ to $54.8 \mathrm{mmHg}\left(\mathrm{T}_{4}\right)$ and a mild decrease in the arterial blood $\mathrm{pH}$ from $7.38\left(\mathrm{~T}_{1}\right)$ to $7.32\left(\mathrm{~T}_{4}\right)$. Detected moderate hypercapnia followed by weak respiratory acidosis (Table 6).

\begin{tabular}{|c|c|c|c|c|c|c|c|c|}
\hline Parameters & \multicolumn{5}{|c|}{$\mathrm{PaCo}_{2}$ (mm Hg+standard deviation) } & \multicolumn{3}{|l|}{$\mathrm{pH}$} \\
\hline & \multicolumn{8}{|l|}{ T-intervals } \\
\hline Groups & T0 & $\mathrm{T} 1$ & $\mathrm{~T} 2$ & T3 & TO & $\mathrm{T} 1$ & T2 & T3 \\
\hline VHV & $38.9 \pm 2.5$ & $45.2 \pm 1.7$ & $36.2 \pm 6.3$ & $33.8 \pm 4.7$ & $7.41 \pm 0.009$ & $7.35 \pm 0.024$ & $7.44 \pm 0.024$ & $7.44 \pm 0.025$ \\
\hline VLV & $42.6 \pm 3.1$ & $57.6 \pm 2.9$ & $87.2 \pm 5.6$ & $98.4 \pm 6.9$ & $7.39 \pm 0.027$ & $7.23 \pm 0.032$ & $7.01 \pm 0.073$ & $7.00 \pm 0.065$ \\
\hline LPV & $37.8 \pm 2.8$ & $45.4 \pm 3.2$ & $51.6 \pm 2.3$ & $54.8 \pm 4.2$ & $7.42 \pm 0.014$ & $7.38 \pm 0.02$ & $7.34 \pm 0.001$ & $7.32 \pm 0.01$ \\
\hline Anova (p) & 0.067 & $<0.01$ & $<0.01$ & $<0.01$ & 0.064 & $<0.01$ & $<0.01$ & $<0.01$ \\
\hline \multicolumn{9}{|c|}{ Tukey HSD ("Honestly Significant Difference") Post-hoc Test (p-value) } \\
\hline VHV $v_{s}$ VLV & 0.174 & $<0.01$ & $<0.01$ & $<0.01$ & 0.235 & $<0.01$ & $<0.01$ & $<0.01$ \\
\hline VHV $v_{s}$ LPV & 0.837 & 0.992 & $<0.01$ & $<0.01$ & 0.672 & 0.199 & $<0.01$ & $<0.01$ \\
\hline
\end{tabular}


Citation: Videnovic N, Mladenovic J, Pavlovic A, Trpkovic S, Nikolic S, et al. (2018) Protective Lung Ventilation Strategy Combined with Prone Position in the Treatment of Severe Pulmonary Aspiration Syndrome: An Experimental Study. J Vet Sci Technol 9: 549. doi: $10.4172 / 2157-7579.1000549$

Page 6 of 9

\begin{tabular}{|l|l|l|l|l|l|l|l|l|}
\hline VLVs v SPV $_{\mathrm{s}}$ & 0.068 & $<0.01$ & $<0.01$ & $<0.01$ & 0.057 & $<0.01$ & $<0.01$ & $<0.01$ \\
\hline
\end{tabular}

Table 6: Review of mean values of carbon dioxide in the arterial blood of experimental animals $\left(\mathrm{PaCO}_{2}\right)$ and arterial blood pH by time stages $(\mathrm{T})$ of research and testing the significance of differences between study groups using Anova and Tukey HSD Post-hoc Test. \#VHV-Ventilation High Volume; VLV-Ventilation Low Volume; LPV-Lung Protective Ventilation; $\mathrm{p}>0.05$ non-significant; $\mathrm{p}<0.05$ significant; $\mathrm{p}<0.01$ highly significant.

Table 7 shows the values of $\mathrm{SaO}_{2}$ and $\mathrm{PaO}_{2}$ over monitoring intervals. The largest decline in these values was recorded after infusion of gastric juice into the lungs of the piglets $\left(\mathrm{T}_{1}\right)$. By the time of pulmonary ventilation, there was a gradual increase in the values of
$\mathrm{SaO}_{2}$ and $\mathrm{PaO}_{2}$. The increase was most pronounced in LPV group $\left(\mathrm{SaO}_{2}: 78.2 \%\left(\mathrm{~T}_{1}\right)-93.4 \%\left(\mathrm{~T}_{4}\right) ; \mathrm{PaO}_{2}: 59.2 \mathrm{mmHg}\left(\mathrm{T}_{1}\right)-91.6 \mathrm{mmHg}\right.$ $\left(\mathrm{T}_{4}\right)$.

\begin{tabular}{|c|c|c|c|c|c|c|c|c|}
\hline \multirow[t]{2}{*}{ Parameters } & \multicolumn{4}{|c|}{$\mathrm{SaO}_{2}(\%+$ standard deviation $)$} & \multicolumn{4}{|c|}{$\mathrm{PaO}_{2}$ (mmHg+standard deviation) } \\
\hline & \multicolumn{8}{|c|}{ T-intervals } \\
\hline Groups & T0 & $\mathrm{T} 1$ & T2 & T3 & T0 & T1 & $\mathrm{T} 2$ & T3 \\
\hline VHV & $99.2 \pm 0.83$ & $88.1 \pm 1.87$ & $90 \pm 1.22$ & $89.6 \pm 0.89$ & $97.3 \pm 2.4$ & $65.2 \pm 4.1$ & $76 \pm 3.9$ & $75.4 \pm 4.9$ \\
\hline VLV & $99 \pm 0.71$ & $76.2 \pm 3.27$ & $81.4 \pm 3.84$ & $83 \pm 3.53$ & $96.4 \pm 4.1$ & $55.4 \pm 4.8$ & $62.8 \pm 2.5$ & $71.4 \pm 4.3$ \\
\hline LPV & $99.1 \pm 0.65$ & $78.2 \pm 2.16$ & $87.2 \pm 1.92$ & $93.4 \pm 1.14$ & $97.2 \pm 4.1$ & $59.2 \pm 5.3$ & $72.4 \pm 4.9$ & $91.6 \pm 3.8$ \\
\hline Anova (p) & 0.912 & $<0.01$ & $<0.01$ & $<0.01$ & 0.912 & 0.021 & $<0.01$ & $<0.01$ \\
\hline \multicolumn{9}{|c|}{ Tukey HSD ("Honestly Significant Difference") Post-hoc Test (p-value) } \\
\hline VVV vs VLV & 0.903 & $<0.01$ & $<0.01$ & $<0.01$ & 0.919 & 0.017 & $<0.01$ & 0.347 \\
\hline VVV vs LPV & 0.974 & $<0.01$ & 0.227 & 0.045 & 0.999 & 0.156 & 0.342 & $<0.01$ \\
\hline VLV vs LPV & 0.974 & 0.442 & $<0.01$ & $<0.01$ & 0.935 & 0.441 & $<0.01$ & $<0.01$ \\
\hline
\end{tabular}

Table 7: Review of mean values of saturation of hemoglobin in arterial blood $\left(\mathrm{SaO}_{2}\right)$ and partial pressure of oxygen in arterial blood $\left(\mathrm{PaO}_{2}\right)$ by time stages $(\mathrm{T})$ of research and testing the significance of differences between study groups using Anova and Tukey HSD Post-hoc Test. \#VHVVentilation High Volume; VLV-Ventilation Low Volume; LPV-Lung Protective Ventilation; $p>0.05$ non-significant; $p<0.05$ significant; $p<0.01$ highly significant.

The entry of gastric juice into small airways, their resulting obstruction, spasm in bronchi and bronchioles, alveolar and interstitial edema, alveolar collapse and occurrence of micro atelectasis caused a pathological increase of intrapulmonary shunt (Qs/Qt). With the duration of mechanical ventilation, the ventilation protocols applied in the tested groups had different effects on intrapulmonary shunt values (as shown in Table 8).

\begin{tabular}{|c|c|c|c|c|}
\hline Parameters & \multicolumn{4}{|c|}{ Qs/Qt (\%+standard deviation) } \\
\hline \multicolumn{5}{|l|}{ T-intervals } \\
\hline Groups & $\mathrm{T}_{0}$ & $\mathrm{~T}_{1}$ & $\mathrm{~T}_{2}$ & $T_{3}$ \\
\hline VHV & $3.3 \pm 2.9$ & $23.1 \pm 3.9$ & $25.3 \pm 3.2$ & $26.5 \pm 4.8$ \\
\hline VLV & $4.7 \pm 3.7$ & $36 \pm 3.2$ & $31.4 \pm 3.8$ & $28.4 \pm 3.5$ \\
\hline LPV & $3.9 \pm 3.1$ & $31.2 \pm 2.7$ & $21.2 \pm 2.9$ & $13.4 \pm 4.1$ \\
\hline Anova & 0.795 & $<0.01$ & $<0.01$ & $<0.01$ \\
\hline \multicolumn{5}{|c|}{ Tukey HSD ("Honestly Significant Difference") Post-hoc Test (p-value) } \\
\hline VHV $v_{s}$ VLV & 0.778 & $<0.01$ & 0.032 & 0.756 \\
\hline VHV $v_{s} L P V$ & 0.954 & $<0.01$ & 0.166 & $<0.01$ \\
\hline
\end{tabular}


Citation: Videnovic N, Mladenovic J, Pavlovic A, Trpkovic S, Nikolic S, et al. (2018) Protective Lung Ventilation Strategy Combined with Prone Position in the Treatment of Severe Pulmonary Aspiration Syndrome: An Experimental Study. J Vet Sci Technol 9: 549. doi: $10.4172 / 2157-7579.1000549$

Page 7 of 9

\begin{tabular}{|l|l|l|l|l|}
\hline VLV $v_{\mathrm{S}}$ LPV & 0.92 & 0.094 & $<0.01$ & $<0.01$ \\
\hline
\end{tabular}

Table 8: Review of mean values of the intrapulmonary shunt (Qs/Qt) by time stages (T) of research and testing the significance of differences between study groups using Anova and Tukey HSD Post-hoc Test. \#VHV-Ventilation High Volume; VLV-Ventilation Low Volume; LPV-Lung Protective Ventilation; $\mathrm{p}>0.05$ non-significant; $\mathrm{p}<0.05$ significant; $\mathrm{p}<0.01$ highly significant.

\section{Discussion}

Since the risk of pulmonary aspiration was recognized in obstetric anesthesia, numerous efforts have been made to reduce the incidence and severity of perioperative pulmonary aspiration: preoperative fasting, preoperative assessment of risk factors in perioperative pulmonary aspiration, emptying the stomach, rapid-sequence induction of anesthesia with cricoid pressure, and the use of a cuffed tracheal tube. With these efforts, the incidence of pulmonary aspiration has been reduced drastically, and aspiration is now rare [14].

Nevertheless, recent large studies have shown that perioperative pulmonary aspiration is the main cause of anesthesia-related death or irreversible brain damage [14,15]. The true incidence of aspiration induced lung injury is difficult to estimate considering that most aspiration events are silent or un-witnessed.

Acute lung injury/acute respiratory distress syndrome (ALI/ARDS) typically involves a sudden, severe pulmonary inflammation and alveolar-capillary permeability injury that includes proteinaceous edema, hypoxemia, loss of lung compliance, and is also frequently associated with multi-organ system failure [16]. The severity of lung injury following gastric aspiration ranges from a mild, subclinical pneumonitis to a progressive respiratory failure with significant morbidity and mortality. Gastric aspiration is a major direct cause of ALI and the more severe ARDS [16,17].

Early identification of patients at risk for developing ARDS and implementation of preventive strategies becomes an important approach for critically ill patients admitted to intensive care units, particularly patients receiving mechanical ventilation [18].

The results of this study indicate that the applied mechanical ventilation strategies did not produce identical changes in the lung microstructure. Ventilation at a volume of $15 \mathrm{ml} / \mathrm{kg}$ body weight resulted in the formation of pronounced alveolar and interstitial edema, distended and ruptured alveolus, air leaks in the lung tissue, pronounced cellular infiltration with occurrence of bleeding in the lung tissue. However, in addition to these patho histological changes resulting from the compound effect of aspirated content and the applied strategy of mechanical ventilation of the lungs (large $V_{t}$, high $\mathrm{P}_{\text {plato }}$ ), polymorphism of the histological findings was complemented by changes in the form of alveolar collapse and micro atelectasis (more pronounced in the dorsal lung regions).

In contrast to the effect of a high tidal volume on structural changes in the pulmonary tissue, ventilation at low $V_{t}$ gave a completely different picture of patho histological changes with prevalent micro atelectasis, alveolar collapse, pronounced cellular infiltration of interstitial and alveolar spaces. In this group we also observed parts of the lung tissue with an almost normal microscopic structure (ventral lung regions) but in lower incidence.

Polymorphism of structural changes in the lungs was least pronounced in the group with lung protective ventilation applied. The absence of alveolar and interstitial edema, micro atelectasis, significant cellular infiltration, with simultaneous predominance of pulmonary regions of moderately distended alveoli and dilated small airways enabled preservation of a large surface of the alveolar-capillary membrane necessary for maintaining homeostasis and the respiratory component of acid-base balance. Preserved respiratory membrane and applied mechanical ventilation in this group of experimental animals resulted in gradual normalization of the parameters of ventilation, oxygenation and acid-base status. The incidence of moderate hypercapnia can be resolved by increasing the frequency and minute respiratory ventilation with the consequent effect on the $\mathrm{pH}$ of the arterial blood.

The progression, both in terms of pre-existing and occurring patho histological changes in the piglets of VHV and VLV groups, led to great reduction in the surface of the alveolar-capillary membrane necessary for gas exchange in the lungs. In the VLV group this was manifested by hypoxemia, severe hypercapnia, and respiratory acidosis. Initially, hypercapnia and respiratory acidosis were handled by increasing the frequency and minute ventilation, but as the changes developed, this adaptive mechanism was lost.

For certain amount of time, high tidal volume allowed for the parameters of ventilation, Oxygenation and $\mathrm{pH}$ of arterial blood to be within the physiological limits. However, with further progression of lung injury and the development of severe ARDSs, the lungs would become insufficient and incapable of maintaining the homeostasis and the respiratory component of the acid-base status.

Potentially injurious ventilator settings might be associated with secondary development of ARDS in mechanically ventilated patient without ARDS at the onset. Observational studies demonstrated that high tidal volume and $\mathrm{P}_{\text {plat }}$ are major risk factors for the secondary development of ARDS [19]. Over distention due to a high tidal volume $\left(V_{t}\right)$ or end inspiratory pressures and the repeated opening and closing of distal bronchi and unstable alveoli resulting in high stress and strain have been proposed as the main physical mechanisms responsible for VILI [20]. The use of low tidal volume instead of a large one led to a marked effect on survival in a large prospective, randomized, multicenter trial of patients with acute respiratory distress syndrome (ARDS), initiating the era of low tidal volume ventilation or protective ventilation [21].

Today, numerous studies and meta-analyzes support the concept of open lungs in patients with severe ARDSs using a positive endexpiratory pressure in order to correct refractory hypoxemia [22-24]. However, whether high levels of positive end-expiratory pressure prevent ventilator induced lung injury is still controversial.

High intra-pulmonary shunt values are recorded in all three tested groups after the aspiration of gastric juice into the lungs of the piglets. However, ventilation at low tidal volume $(6 \mathrm{ml} / \mathrm{kg}$ body weight $)$ and positive end-expiratory pressure $\left(5-10 \mathrm{~cm} \mathrm{H}_{2} \mathrm{O}\right)$ over the next seven hours kept these values within physiological levels, which was not the case in the other two study groups. In the LPV group, normalization of the intra-pulmonary shunt was accompanied by significant increase in $\mathrm{SaO}_{2}$ and $\mathrm{PaO}_{2}$ values. 
Citation: Videnovic N, Mladenovic J, Pavlovic A, Trpkovic S, Nikolic S, et al. (2018) Protective Lung Ventilation Strategy Combined with Prone Position in the Treatment of Severe Pulmonary Aspiration Syndrome: An Experimental Study. J Vet Sci Technol 9: 549. doi: $10.4172 / 2157-7579.1000549$

Page 8 of 9

In 1988, Langer et al. reported on the effects of prone positioning on oxygenation in 13 ARDS patients, mostly primary lung injury (direct lung injury mainly stemming from pneumonia or aspiration), who received higher PEEP and lower $\mathrm{FiO}_{2}$ [25]. The improvement in oxygenation in the prone position is due to a reduction in intrapulmonary shunt [26] and results from the concomitant effect of the increase in aeration in the dorsal lung regions, which was greater than the loss of aeration in the ventral regions and the prevalence of lung perfusion into those dorsal regions. The fact that blood continues to flow towards the dorsal regions in the prone position has been demonstrated in many studies. Therefore, the reduction in intrapulmonary shunt is due to more ventilation in well-perfused lung areas [27]. The second rationale to use prone positioning is in the prevention of VILI $[27,28]$. Analysis of high-quality evidence showed that mechanical ventilation in the prone position significantly reduced mortality among patients with ARDS who received protective lung ventilation. This technique was beneficial to patients with moderate to severe ARDS when used for prolonged periods of 16 hours or more each day [29]. Prone positioning during mechanical ventilation is not without risks. Study Sud et al. showed that patients in the prone group were at increased risk of pressure ulcers and obstruction of the endotracheal tube [29].

\section{Conclusion}

The selection of an inadequate strategy of mechanical ventilation of the lungs in the treatment of aspiration syndrome intensifies lung injury in the form of the onset and development of severe polymorphic patho-histological changes. The resulting lung injury, over time, leads to respiratory failure.

Ventilation at low tidal volume and positive end-expiratory pressure, applied in the first hours of development of aspiration syndrome, can prevent and / or reduce the progression and degree of lung injury. This favorably reflects on the lung's sufficiency to maintain the homeostasis, oxygenation, and the respiratory component of the acid-base status. This effect of protective ventilation of the lungs is maximized by prone position in experimental animals.

\section{Protection of Humans and Animals}

The study was approved by ethical committee of Faculty of Medicine in Pristina-Kosovska Mitrovica and Clinical Centre in Gracanica, and conducted in line with international and national regulations and guidelines for the use of animals in experimental research.

\section{Conflict of Interest}

The authors declare that there is no conflict of interests regarding the publication of this paper.

\section{Funding Sources}

This research received no specific grant from any funding agency in the public, commercial, or not-for-profit sectors.

\section{References}

1. Marik PE (2011) Pulmonary aspiration syndromes. Curr Opin Pulm Med 17: 148-154.

2. de Benedictis FM, Carnielli VP, de Benedictis D (2009) Aspiration lung disease. Pediatr Clin North AM 56: 173-90.
3. Saito $\mathrm{T}$ (2016) Risk Factors of Perioperative Pulmonary Aspiration Related to Anesthesia, Devices and Operation. Masui 65: 29-36.

4. Mori Y, Sumikura H (2016) Prophylaxis of Pulmonary Aspiration during General Anesthesia. Masui 65: 42-49.

5. Hunt EB, Sullivan A, Galvin J, MacSharry J, Murphy DM (2018) Gastric Aspiration and Its Role in Airway Inflammation. Open Respir Med J 12: 1-10.

6. Brownlee IA, Aseeri A, Ward C, Pearson JP (2010) From gastric aspiration to airway inflammation. Monaldi Arch Chestt Dis 73: 54-63.

7. Abdulla S (2013) Pulmonary aspiration in perioperative medicine. Acta Anaesthesiol Belg 64: 1-13.

8. Slutsky AS (1999) Lung injury caused by mechanical ventilation. Chest 116: 9S-15S.

9. Gajic O, Dara SI, Mendez JL, Adesanya AO, Festic E, et al. (2004) Ventilator-associated lung injury in patients without acute lung injury at the onset of mechanical ventilation. Crit Care Med 32: 1817-1824.

10. Kolobow T (2004) Volutrauma, barotrauma, and ventilator-induced lung injury: lessons learned from the animal research laboratory. Crit Care Med 32: 1961-62.

11. Cruz FF, Ball L, Rocco PRM, Pelosi P (2018) Ventilator-induced lung injury during controlled ventilation in patients with acute respiratory distress syndrome: less is probably better. Expert Rev Respir Med 12: 403-414.

12. Whitehead T, Slutsky AS (2002) The pulmonary physician in critical care 7: Ventilator induced lung injury. Thorax 57: 635-642.

13. Dreyfuss D, Saumon G (1998) Ventilator-induced lung injury, Lessons from experimental studies. Am J Respir Crit Care Med 157: 294-323.

14. Asai $\mathrm{T}$ (2016) Perioperative Pulmonary Aspiration: Preface and Comments. Masui 65: 2-3.

15. Robinson M, Davidson A (2014) Aspiration under anaesthesia: risk assessment and decision-making. Contin Edu Anaes, Critic Care \& Pain 14: 171-175.

16. Raghavendran K, Nemzek J, Napolitano LM, Knight PR (2011) Aspiration-induced lung injury. Crit Care Med 39: 818-826.

17. Sweeney RM, McAuley DF (2016) Acute respiratory distress syndrome. Lancet 388: 2416-2430.

18. Rittayamai N, Brochard L (2015) Recent advances in mechanical ventilation in patients with acute respiratory distress syndrome. Eur Respir Rev 24: 132-40.

19. Neto AS, Simonis FD, Barbas CS, Biehl M, Determann RM, et al. (2014) Association between tidal volume size, duration of ventilation and sedation needs in patients without acute respiratory distress syndrome: an individual patient data meta-analysis. Intensive Care Med 40: 950-957.

20. Bugedo G, Retamal J, Bruhn A (2017) Does the use of high PEEP levels prevent ventilator-induced lung injury? Rev Bras Ter Intensiva 29: 231-237.

21. Brower RG, Matthay MA, Morris A, Schoenfeld D, Thompson BT, et al. (2000) Ventilation with lower tidal volumes as compared with traditional tidal volumes for acute lung injury and the acute respiratory distress syndrome. N Engl J Med 342: 1301-1308.

22. Gattinoni L, Caironi $P$ (2008) Refining ventilatory treatment for acute lung injury and acute respiratory distress syndrome. JAMA 299: 691-693.

23. Kacmarek RM, Villar J, Sulemanji D, Montiel R, Ferrando C, et al. (2016) Open Lung Approach for the Acute Respiratory Distress Syndrome: A Pilot, Randomized Controlled Trial. Crit Care Med 44: 32-42.

24. Briel M, Meade M, Mercat A, Brower RG, Talmor D, et al. (2010) Higher vs lower positive end-expiratory pressure in patients with acute lung injury and acute respiratory distress syndrome: systematic review and meta-analysis. JAMA 303: 865-873.

25. Langer M, Mascheroni D, Marcolin R, Gattinoni L (1988) The prone position in ARDS patients: A clinical study. Chest 94: 103-107.

26. Oeckler RA, Hubmayr RD (2007) Ventilator-associated lung injury: a search for better therapeutic targets. Eur Respir J 30: 1216-1226. 
Citation: Videnovic N, Mladenovic J, Pavlovic A, Trpkovic S, Nikolic S, et al. (2018) Protective Lung Ventilation Strategy Combined with Prone Position in the Treatment of Severe Pulmonary Aspiration Syndrome: An Experimental Study. J Vet Sci Technol 9: 549. doi: $10.4172 / 2157-7579.1000549$

Page 9 of 9

27. Guerin C (2014) Prone ventilation in acute respiratory distress syndrome. Eur Respir Rev 23: 249-257.

28. Slutsky AS, Ranieri VM (2013) Ventilator-induced lung injury. N Engl J Med 369: 2126-2136.
29. Sud S, Friedrich JO, Adhikari NK, Taccone P, Mancebo J, et al. (2014) Effect of prone positioning during mechanical ventilation on mortality among patients with acute respiratory distress syndrome: a systematic review and meta-analysis. CMAJ 186: 381-390. 